\title{
A clinical study on antrochoanal polyps with special reference to endoscopic evaluation
}

\author{
Dhananjay Kumar ${ }^{1}$, Manoj Kumar²*
}

${ }^{1}$ Senior Resident, ${ }^{2}$ Assistant Professor, Department of ENT, Darbhanga Medical College and Hospital, Bihar, INDIA. Email: manojdrbhu77@yahoo.co.in

$\underline{\text { Abstract }}$

\begin{abstract}
Background: Antrochoanal polyps (ACPs) are benign polypoid lesions arising from the oedematous mucosa of the maxillary antrum and they extend through the maxillary ostium into the middle meatus and thereafter protruding posteriorly to the choana and nasopharynx. Children and young adults are more prone to antrochoanal polyps and are unilateral almost every time. The etiopathogenesis of ACPs are not known clearly. The most common clinical presentations related to ACPs are nasal obstruction and nasal drainage. Methods: Here 50 patients with antrochoanal polyps (ACPs). All 50 patients underwent preoperative radiological assessment through CT scan. All of them were subjected to surgical removal. Surgery was performed exclusively by nasal endoscopy, and the polyps were removed under general anesthetic using functional endoscopic sinus surgery (FESS) of the maxillary ostium for removal of the ACPs. Results: The most common clinical finding was unilateral nasal obstruction followed by nasal mass and rhinorrhoea. Endoscopic findings showed the polyps passed through the main ostium in 23 patients, while the polyps passed through the accessory ostium in 5 patients and in 2 patients the origin could not be assessed. Recurrence was reported in $3(10 \%)$ cases. Conclusion: Endoscopic assessment and CT scan for diagnosing antrochoanal polyps are the gold standard techniques. Endoscopic surgery should be the choice as surgical treatment for ACPs is mandatory.
\end{abstract}

Key Word: antrochoanal polyps, endoscopic evaluation.

*Address for Correspondence:

Dr Manoj Kumar, Assistant Professor, Department of ENT, Darbhanga Medical College and Hospital, Bihar, INDIA.

Email: manojdrbhu77@yahoo.co.in

Received Date: 04/11/2019 Revised Date: 17/12/2019 Accepted Date: 28/01/2020

DOI: https://doi.org/10.26611/10161514

This work is licensed under a Creative Commons Attribution-NonCommercial 4.0 International License. (cc)) EY-NC

\begin{tabular}{|l|l|}
\hline \multicolumn{2}{|c|}{ Access this article online } \\
\hline Quick Response Code: & Website: \\
& www.medpulse.in \\
\hline
\end{tabular}

\section{INTRODUCTION}

Antrochonal ployp (ACP) was first described in detail by Professor Gustav Killian in 1906 though the first case was reported by Palfyn in $1753^{1,2}$. ACPs are atopic benign lesions originating from from the maxillary sinus mucosa prolepses into the nasal cavity through the maxillary ostium (either the true ostium or the accessory ostium) and capable of extending to the choana and nasopharyn $x^{3}$ Several pathogenic mechanism have been proposed earlier to find out the reason behind the development of ACPs, but their cause is still not completely known and they are subjected to contradiction ${ }^{4}$. Some studies found significant correlation with allergy and ACPs. But some studies reported that there is no role of allergy in the etiology of ACPs, and they can be chronic inflammatory processes rather than allergy ${ }^{[5,6]}$. Although, the exact etiology of antrochoanal polyps is unknown a case report of 200 antrochoanal polyos reported that the only significant risk factor is anatomic anomally ${ }^{4}$. Nasal septal deviation, inferior turbinate hypertrophy and croncha bullosa were the most common aabnormalities reported by the authors ${ }^{4}$. The antrochoanal polyps are more frequently found in children and adolescents rather than adults. It was reported that ACPs constitute $4-6 \%$ of adult polyps while upto $42 \%$ of all nasal polyps in children ${ }^{4,7,8}$. ACPs are generally unilateral occurrence, bilateral antrochoanal polyps are extremely rare ${ }^{9}$. Nasal endoscopy and CT scan are considered as the gold standard techniques for the diagnosis of antrachoanal polyps. In case of antrachoanal polyps a CT scan shows a hypodense mass arising from an enlarged, opacified maxillary sinus ${ }^{8}$. The polyps may not cause bony destruction but they can axpand and enlarge the ostium. ${ }^{10}$ The site of the poly and its soft consistency causes its dumbbell shape. Surgical treatment is the only 
definitive option for treatment of ACPs and in earlier studies several techniques have been described. ${ }^{4}$ While doing the surgery it is important to ensure the complete removal of the whole unlike a simple polypectomy, because of the high rate of recurrence. The Caldwell-Luc approach was performed to ensure the complete removal of the polyp and the antral mucosa. However, the Cald-Luc technique has fallen from favour due to associated complications such as facial parasthesia, injury of the infra-orbital nerve, cheek anaesthesia and swelling, and carries risks to developing teeth and damaging the maxillary growth centers in children ${ }^{11,12}$. Since its introduction functional endoscopic surgery (FESS) has become the treatment of choice for ACPs. ${ }^{13}$ This technique involves the complete removal of not only the solid nasal portion but the cystic antral portions of the polyp as well. With this technique the risk of complications and recurrence can be reduced as some previous studies reported complete resolution. ${ }^{12}$ Usually the recurrence rate can be upto $15 \%$ depending on the surgical treatment ${ }^{14}$. The purpose of the present study is to assess the endoscopic evaluation among patients with antrochoanal polyps.

\section{METHODS}

The present study was conducted in the Department of ENT, Darbhanga Medical College and Hospital, bhar, India during the study period of January 2019 to December 2019. A total of 30 patients were included in the study. Age rangead varied from below 1 year to 60 years.

Inclusion Criteria:

- Patients diagnosed with antrochoanal polyps.

- Patients aged between below 1 year to 60 years of either sex.

- Patients with unilateral antrochoanal polyp.

Exclusion Criteria:

- Patients presenting with congenital nasal mass or nasal mass, of intra cranial origin such as basal meningocoele, basal meningo-encephalocele and nasal glioma

Preoperative Assessment: After obtaining the written consent form from either the patients or the guardians all the study participants were subjected to preoperative radiological evaluation by $\mathrm{CT}$ scan of the nose and paranasal sinuses with both axial and coronal cuts do determine the extent of the disease. Anatomical variants of the middle turbinate, dehiscence of the lamina papyracea and relation to the optic nerve were identified.

Surgical Procedure: All the patients underwent endoscopic sinus surgery. Endoscopic sinus surgery was performed under general or local anesthesia. AKP was complete excision of the polyp along with the antral mucosa. Ethical approval permission taken from Institutional Ethical Committee.

\section{RESULTS}

A total number of 30 patients of antrochoanal polyps were studied during the one-year period. The following observations were made and analysed:

In the present study antrochoanal polyps had an incidence of maximum $40 \%$ in the age group of $11-20$ years, followed by the incidence of $33.3 \%$ in the age group of 21 30 years and incidence of $10 \%$ in the age group of $41-50$ years. The least common age groups were 31-40 years and 51-60 years with the incidence of $6.7 \%$ in each group. We observed an overall male predominance with the ratio of 1.5:1.

The most common clinical presentation was nasal obstruction (100\%) followed by nasal mass (83.3\%), rhinorrhoea (73.3) and obstructive sleep apnoea or snoring $(60 \%)$. The least common clinical findings were post nasal discharge (30\%), smell disturbances (26.7), epistaxis $(10 \%)$, sneezing $(6.7 \%)$ and headache $(6.7 \%)$. Regarding duration of symptoms we found in the present study maximum $40 \%$ of the patients had symptoms for $0-6$ months(Table 1).

\begin{tabular}{|c|c|c|}
\hline Parameters & Frequency & Percentage \\
\hline \multicolumn{3}{|c|}{ Age } \\
\hline $0-10$ & 1 & 3.3 \\
\hline $11-20$ & 12 & 40.0 \\
\hline $21-30$ & 10 & 33.3 \\
\hline $31-40$ & 2 & 6.7 \\
\hline $41-50$ & 3 & 10.0 \\
\hline $51-60$ & 2 & 6.7 \\
\hline \multicolumn{3}{|c|}{ Gender } \\
\hline Male & 18 & 60.0 \\
\hline Female & 12 & 40.0 \\
\hline \multicolumn{3}{|c|}{ Clinical Presentation } \\
\hline Unilateral Nasal Obstruction & 30 & 100.0 \\
\hline Nasal Mass & 25 & 83.3 \\
\hline Rhinorrhoea & 22 & 73.3 \\
\hline Sleep apnoea or snoring & 18 & 60.0 \\
\hline Post Nasal Discharge & 9 & 30.0 \\
\hline Smell disturbances & 8 & 26.7 \\
\hline Epistaxis & 3 & 10.0 \\
\hline Sneezing & 2 & 6.7 \\
\hline Headache & 2 & 6.7 \\
\hline \multicolumn{3}{|c|}{ Duration of Symptoms (months) } \\
\hline $0-6$ & 12 & 40.0 \\
\hline $7-12$ & 11 & 36.7 \\
\hline $13-24$ & 5 & 16.7 \\
\hline$>24$ & 2 & 6.7 \\
\hline
\end{tabular}

ACPs were on the right side in 17 (56.7\%) patients and on the left side in 13 (43.3\%) patients. Regarding the origins and attachments of the pedicle in the antrum are as follows: posterior and lateral walls in $16(46.7 \%)$ patients, medial wall $6(20 \%)$ patients and inferior wall in $2(6.7 \%)$ patients. 
The exact attachment could not be assessed in 4 (13.3\%) cases as the antrum was filled with diffuse polypoidal mucosa. In 23 (76.7\%) patients the polyps passed through the main ostium, while the polyps passed through the accessory ostium in $5(16.7 \%)$ patients and in 2 patients the origin could not be assessed due to associated ethmoiditis. Regarding nasal anatomical defects we found 16 (53.3\%) had septal deviation, inferior turbinate hypertrophy was found in $6(20 \%)$ patients, and concha bulosa in $2(6.7 \%)$ patients. Only $6(20 \%)$ patients were presented without any nasal anatomical abnormalities(Table 2).

Table 2: Pre-operative Endoscopic Findings

\begin{tabular}{|c|c|c|}
\hline Parameters & Frequency & Percentage \\
\hline \multicolumn{3}{|c|}{ Side of Involvement } \\
\hline Right & 17 & 56.7 \\
\hline Left & 13 & 43.3 \\
\hline \multicolumn{3}{|c|}{ Nasal anatomical defects } \\
\hline Septal deviation & 16 & 53.3 \\
\hline Inferior turbinate Hypertrophy & 6 & 20.0 \\
\hline Concha Bulosa & 2 & 6.7 \\
\hline No Defect & 6 & 20.0 \\
\hline \multicolumn{3}{|c|}{ Attachments } \\
\hline Posterior and lateral wall & 14 & 46.7 \\
\hline Medial wall & 10 & 33.3 \\
\hline Inferior wall & 2 & 6.7 \\
\hline Not detected & 4 & 13.3 \\
\hline \multicolumn{3}{|c|}{ Origin } \\
\hline Main ostium & 23 & 76.7 \\
\hline Accessory ostium & 5 & 16.7 \\
\hline Not assessed & 2 & 6.7 \\
\hline
\end{tabular}

Histopathological patterns of the antrochoanal polyps showed inflammatory and allergic type was observed in 22 $(73.3 \%)$ and $8(26.7 \%)$ patients respectively(Table 3 ).

Table 3: Histopathological Patterns of Antrochoanal Polyps

\begin{tabular}{ccc}
\hline Types & Frequency & Percentage \\
\hline $\begin{array}{c}\text { Inflammatory (Neutrophils+Plasma } \\
\text { cell Predominance) }\end{array}$ & 22 & 73.3 \\
$\begin{array}{c}\text { Allergic (Eosiniphil predominance) } \\
\text { (E) }\end{array}$ & 8 & 26.7 \\
\hline
\end{tabular}

Associated concurrent nasal pathology showed 10 (33.3\%) patients had ethmoiditis, 5 (16.7\%) had inferior turbinate hypertrophy, 4 (13.3\%) patient had concha bulosa, $3(10 \%)$ patients had choanal adenoids and $2(6.7 \%)$ patients had septal spur (Table 4). All these lesions were managed endoscopically along with ACPs. Recurrence was reported in $3(10 \%)$ cases.

Table 4: Associated Concurrent Nasal Pathology

\begin{tabular}{ccc}
\hline Types & Frequency & Percentage \\
\hline Ethemoiditis & 10 & 33.3 \\
Hypertrophied inferior turbinate & 5 & 16.7 \\
Choncha bullosa & 4 & 13.3 \\
Choanal adenoids & 3 & 10.0 \\
Septal spur & 2 & 6.7 \\
\hline
\end{tabular}

\section{DISCUSSION}

Antrochoanal polyps are usually seen in young adults and children. They involves 4-6\% of adult polyps while up to $33 \%$ of chilhod polyps ${ }^{15}$. The usually originates from the maxillary sinus but sometimes can also occur in accessory ostium. They also have been reported to originate in the sphenoid, posterior ethmoid and frontal sinuses ${ }^{16}$. The etiopathogenesis of ACPs are still unclear ${ }^{17}$. Berg et al. in 1988hypothesized that ACPs could develop from an antral cyst. ${ }^{18}$ Forsini et al. in his recent study with 200 cases reported that in a patient with a pre-existing antral cyst, and correlation of inflammatory anatomical alteration at ostiomeatal complex or middle meatus level can force the polyp to herniated outside through the accessory ostium ${ }^{4}$. An important factor to note is that $\mathrm{ACP}$ can be related with same chronic inflammatory condition either allergic or infectious, however the factors of cause and effect remain contradictory $^{19}$. The most frequent symptom is unilateral nasal obstruction. Angiofibroma, nasal glioma, inverted papilloma, mucocele mucus retention cyst, meningoencephalocele, Tornwaldt cyst and nasopharyngeal carcinoma must be considered at differential diagnosis of AP. ${ }^{20}$ There is no clear difference regarding the histology. Polyps have a pseudostratified columnar epithelium. ${ }^{14} \mathrm{CT}$ and/or magnetic resonance imaging (MRI) can be used as imaging techniques at diagnosis. Surgical treatment is mandatory to manage ACPs and endoscopic approach for complete removal is extremely safe and effective ${ }^{21}$ and can be performed under general or local anesthesia. Although the Caldwell-Luc approach provides good visualization of the antral mucosa and polyp, it also associated with potential complications such as facial parasthesia, injury of the infra-orbital nerve, cheek anaesthesia and swelling, and carries risks to developing teeth and damaging the maxillary growth centers in children ${ }^{13,22}$. Endoscopic resevtion is the primary treatment today. The primary aim of FESS is complete removal of the polyp (both nasal and antral parts). Endoscopic surgery is commonly used in pathologies of the nose and sinuses since this best preserves the physiology and involves no impairment of cosmetic appearance. AP can be extracted and the osteomeatal region cleansed using the endoscopic method $^{23}$. The antral part of the polyp must be removed from where the polyp originates in order to prevent recurrence $^{24}$. Septal deviation, inferior turbinate hypertrophy and concha bullosa may also be co-present with AP, and these problems can be eliminated in the same session $^{25}$.

\section{CONCLUSION}

Endoscopic sinus surgery is a safe and effective procedure for the complete removal of antrochoanal polyps (ACPs). 
It is also effective in the complete removal of the antral part of the polyp, in the treatment of concomitant pathologies in the maxillary sinus, for the preservation of healthy sinus mucosa. Endoscopic surgery should be the choice as surgical treatment for ACPs is mandatory.

\section{REFERENCE}

1. Palfyn J (1753) Anatomie Chirurgicale, Paris, UK.

2. Killian G (1906) The origin of choanal polypi. Lancet 2: 81-82.

3. Choudhury N, Hariri A, Saleh H (2015) Endoscopic management of antrochoanal polyps: a single UK centre's experience. Eur Arch Otorhinolaryngol 272(9): 23052311.

4. Frosini P, Picarella G, De Campora E. Antrochoanal polyp: analysis of 200 cases. Acta Otorhinolaryngol Itali 2009;29:21-6.

5. $\mathrm{O}$ zcan $\mathrm{C}$, Zeren $\mathrm{H}$, Talas DU, et al... Antrochoanal. polyp: a transmission electron and light microscopic study. Eur Arch Otorhinolaryngol 2005;262:55-60.

6. Skladzien J, Litwin JA, Nowogrodzka-Zagorska M, et al... Morphological and clinical characteristics of antrochoanal polyps: comparison with chronic inflammation-associated polyps of the maxillary sinus. Auris Nasus Larynx201;28:137-41.

7. Segal N., et al... "Nasal polyps in the pediatric population". BENT 8.4 (2012): 265-267.

8. Al-Mazrou KA., et al... "Characteristics of antrochoanal polyps in the pediatric age group". Annals of Thoracic Medicine 4.3 (2009): 133-136.

9. Myatt HM, Cabrera M. Bilateral antrochoanal polyps in a child: a case report. J Laryngol Otol 1996;110:272-4.

10. Yuca K., et al... "Evaluation and treatment of antrochoanal polyps". Journal of Otolaryngology 35.6 (2006): 420-423.

11. Woolley AL, Clary RA, Lusk RP. Antrochoanal polyps in children. Am J Otolaryngol 1996;17:368-73.
12. Yaman H., et al... "Evaluation and Management of Antrochoanal Polyps". Clinical and Experimental Otorhinolaryngology 3.2 (2010): 110-114.

13. Kamel R. Endoscopic transnasal surgery in antrochoanal polyp. Arch Otolaryngol Head Neck Surg 1990;116:8413.

14. Chaiyasate S., et al... "Antrochoanal polyps: How long should follow-up be after surgery?" International Journal of Otolaryngology (2015): 297417.

15. Porcuna DV, Gili JRM, Cabrerizo JRG, Vilas ML, Olmo AP (2008) Unilateral benign choanal polyp: review of 51 patients. Acta Otorrinolaringologica (English Edition) 59(2): 52-56.

16. Cook PR, Davis WE, McDonald R, McKinsey JP (1993) Antrochoanal polyposis: a review of 33 cases. Ear Nose Throat J 72(6): 401-410.

17. Basu SK, Bandyopadhyay SN, Bora H. Bilateral antrochoanal polyps. J Laryngol Otol 2001;115:561-2.

18. Jmeian S. Bilateral Antrochoanal polyps in a child: an extremely rare case. JRMS 2006;13:57-8.

19. SousaW, Pinheiro D, da Silva C, Bastos PC. Bilateral antrochoanal polyps in an adult. Braz J Otorhinolaryngol 2011;77:539.

20. Pruna X, Ibañez JM, Serres X, Garriga V, Barber I, et al... (2000) Antrochoanal polyps in children: CT findings and differential diagnosis. Eur Radiol 10(5): 849-851.

21. Eladl HM, Shawky M. Endoscopic surgery in pediatric recurrent antrochoanal polyp, rule of wide ostium. Int $\mathrm{J}$ Pediatr Otorhinolaryngol 2011;75:1372-5.

22. Schramm VL Jr, Effron MZ (1980) Nasal polyps in children. Laryngoscope 90(9): 1488-1495.

23. Lopatin A, Bykova V, Piskunov G (1997) Choanal polyps: one entity, one surgical approach? Rhinology 35(2): 7983.

24. Tatlipinar A, Gökçeer T, Köksal S, Esen E (2010) Our Clinical Experience In Patients With Isolated Choanal Polyps Reaching Choana. KBB-Forum 9(2): 25-29.

25. De Vuysera S, Hermans R, Marchal G (2001) Sinochoanal polypand its variant, the angiomatous polyp: MRI findings. Eur Radiol 11(1): 55-58.

\section{Source of Support: None Declared Conflict of Interest: None Declared}

Policy for Articles with Open Access:

Authors who publish with MedPulse International Journal of ENT (Print ISSN: 2579-0854) (Online ISSN: 2636-4727) agree to the following terms: Authors retain copyright and grant the journal right of first publication with the work simultaneously licensed under a Creative Commons Attribution License that allows others to share the work with an acknowledgement of the work's authorship and initial publication in this journal.

Authors are permitted and encouraged to post links to their work online (e.g., in institutional repositories or on their website) prior to and during the submission process, as it can lead to productive exchanges, as well as earlier and greater citation of published work. 